\title{
The Distribution of Different Types of Diabetes in Childhood: A Single Center Experience
}

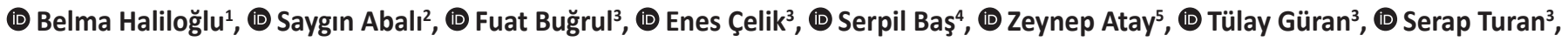 \\ (D) Abdullah Bereket ${ }^{3}$
}

${ }^{1}$ Yeditepe University Faculty of Medicine, Department of Pediatric Endocrinology, Istanbul, Turkey

${ }^{2}$ Acibadem University Faculty of Medicine, Department of Pediatric Endocrinology, Istanbul, Turkey

${ }^{3}$ Marmara University Faculty of Medicine, Department of Pediatric Endocrinology, Istanbul, Turkey

${ }^{4}$ Necip Fazıl City Hospital, Clinic of Pediatric Endocrinology, Kahramanmaraş, Turkey

${ }^{5}$ Medipol University Faculty of Medicine, Department of Pediatric Endocrinology, istanbul, Turkey

\section{What is already known on this topic?}

Although type 1 diabetes is the most common type of diabetes in childhood, a variable increase in the prevalence of type 2 diabetes and maturity onset diabetes of the young has been reported by different multicenter studies depending on the ethnic background, the country of residence and the availability of genetic tests.

\section{What this study adds?}

Information on the distribution of type of diabetes in the Turkish pediatric population is scarce. Comparative data on the clinical characteristics of different types of diabetes, based on the experience of a tertiary pediatric diabetes center over the last 17 years, are presented in this paper. Also, this paper identified a trend towards increase in the frequency of type 2 diabetes in Turkish pediatric population.

\section{Abstract}

Objective: Type 1 diabetes (T1D) is the most common cause of diabetes in childhood but type 2 diabetes (T2D) and maturity onset diabetes of the young (MODY) are emerging as noteworthy causes of diabetes at young ages. The aim is to determine the distribution, trends and clinical features of the different types of diabetes in childhood in one tertiary center.

Methods: The records of children and adolescents aged 0-18 years who were diagnosed as "diabetes/persistent hyperglycemia" between January 1999 and December 2016, were reviewed. Clinical and laboratory characteristics of the patients at diagnosis and type of diabetes were recorded.

Results: The mean \pm standard deviation age of 835 patients $(48.7 \%$ females) at diagnosis was $8.8 \pm 4.4$ years. Eighty-four percent of the patients were diagnosed as T1D, $5.7 \%$ as T2D, $5.3 \%$ as clinical MODY and $5 \%$ as being cases of other types of diabetes. The frequency of diabetic ketoacidosis (DKA) and severe DKA in T1D were $48.4 \%$ and $11.6 \%$, respectively. Fourteen patients (29.2\%) with T2D presented with ketosis and two of them (4.2\%) had DKA at diagnosis. Antibody positivity was $83.1 \%$ in T1D and $14.8 \%$ in T2D. A statistically significant increase in the frequency of T2D has clearly been demonstrated in recent years with a frequency of $1.9 \%, 2.4 \%$ and $7.9 \%$ in 1999-2004, 2005-2010 and 2011-2016, respectively ( $p<0.001$ ). In MODY, genetic analysis was performed in 26 (59\%) patients and HNF1A and GCK gene mutations were detected in $3(11.5 \%)$ and $14(53.8 \%)$ patients, respectively.

Conclusion: Although the most frequent cause of DM is T1D in childhood, a trend towards increase in the frequency of T2D in recent years is notable in our population.

Keywords: Type 1 diabetes, type 2 diabetes, MODY, childhood 


\section{Introduction}

Type 1 diabetes (T1D) is the most common type of diabetes in childhood and its incidence is still rising in various parts of the world (1). However, the increasing worldwide rates of child obesity have also been associated with a variable increase in the prevalence of type 2 diabetes (T2D), depending on the ethnic background and the country of residence (2). While the prevalence of T2D in children was reported as $11 \%$ in the USA (3), this ratio was reported to be lower in Europe (1.3\% in SWEET) (4).

Childhood T2D can be confused with maturity onset diabetes of the young (MODY) due to the presence of a family history, presenting features and a possible confounding factor of obesity/overweight $(5,6)$. Furthermore, MODY, especially due to HNF1A mutations can be misclassified as T1D (7). Determining the type of diabetes is important for therapeutic considerations as well as genetic counseling (8).

The aims of the present study were: 1) to review the etiologic distribution and temporal changes in the etiology of childhood diabetes and; 2) to compare the clinical characteristics of the different types of diabetes encountered in a tertiary pediatric diabetes center over the last 17 years.

\section{Methods}

Data on 927 children and adolescents aged $<18$ years who were diagnosed as "diabetes" or "persistent hyperglycemia" and who were followed-up at the Pediatric Endocrinology and Diabetes Unit of Marmara University Faculty of Medicine in İstanbul, Turkey, between January 1999 and December 2016, were examined. Ninety-two patients with a follow up duration of less than one year were excluded, since the type of diabetes could not be specified because of insufficient data. Finally, 835 patients were included in this single-centered, observational, retrospective study.

The patients' gender, age of diagnosis, height $(\mathrm{cm})$, weight (kg), body mass index (BMI, $\mathrm{kg} / \mathrm{m}^{2}$ ), c-peptide level (ng/ $\mathrm{mL}$ ), presence of pancreatic autoantibodies (islet cell antibodies, glutamic acid decarboxylase antibodies and insulin autoantibodies), presence of ketone bodies, $\mathrm{pH}$ and $\mathrm{HCO}_{3}$ levels at the time of diagnosis, type of diabetes, treatment modalities (diet, oral antidiabetic drug, insulin) were recorded. The patients were classified according to the ISPAD Consensus 2014 (Table 1).

T1D was diagnosed in the presence of severe insulin deficiency, autoantibody positivity and the absence of any suggestive signs of other causes of diabetes. The diagnostic criteria for T2D were based on overweight/obesity, clinical findings of insulin resistance (acanthosis nigricans, hypertension, dyslipidemia), family history of T2D and good metabolic control with metformin or metformin combined with low dose, long-acting insulin $(<0.5 \mathrm{U} /$ $\mathrm{kg} / \mathrm{d}$ ). Patients who had a family history of diabetes of at least two generations in one side of the family, negative autoantibodies, no evidence of insulin resistance and good metabolic control with diet, sulphonylurea or low dose insulin were classified as clinically MODY. HNF1A, HNF4A and GCK genes were analysed for clinically suspected MODY cases. Children with an onset of diabetes before six months of age were diagnosed as neonatal diabetes mellitus (NDM) and relevant genetic tests were performed.

The study was approved by the local Ethical Committee of Marmara University (approval no: 09.2013.0408).

\section{Statistical Analysis}

All statistical data were analyzed using SPSS statistical software for Windows, version 17.0 (SPSS, Chicago, IL). Variables were summarized with descriptive statistics. Data were presented as mean \pm standard deviation (SD). Normality was assessed using the Kolmogorov-Smirnov test. Parametric and nonparametric tests were used for intergroup comparisons. Chi-square test was used for categorical variables. Student's t-test was applied for continuous variables in independent groups. The Mann-Whitney U test was used for continuous variables that did not show normal distribution. The level of statistical significance was set as $p=0.05$.

\section{Results}

After $92 / 927$ patients $(9.9 \%)$ were excluded, the mean age of 835 patients ( $48.7 \%$ females) at diagnosis was $8.8 \pm 4.4$ (median 9.0, range 0.0-18.0) years. Seven hundred and one patients were diagnosed with T1D (84\%), 48 with T2D $(5.7 \%), 44$ with clinical MODY $(5.3 \%)$ and 42 with other types of diabetes (5\%) (Table 1 ).

The clinical characteristics at diagnosis of T1D, T2D and MODY are shown in Table 2. In T1D, 23.7\% $(n=166)$ were younger than age 5 years and $1.6 \%(n=8)$ had a BMI standard deviation score (SDS) $>2$. The frequency of severe diabetic ketoacidosis (DKA) at diagnosis in T1D was $11.6 \%$. T2D was more common in girls and older children. Fourteen patients with T2D (29.2\%) presented with ketosis and two of these $(4.2 \%)$ had DKA at diagnosis. Diabetes autoantibody positivity was $83.1 \%$ in T1D and $14.8 \%$ in T2D. The patients with antibody-positive T2D were compared with those with antibody-negative T2D in terms of age, BMI SDS, presence of DKA and use of insulin. The only statistically significant 
Table 1. The distribution of the patients with diabetes

\begin{tabular}{lll} 
& $\mathrm{n}$ & $\mathbf{\%}$ \\
\hline T1D & 701 & 84 \\
T2D & 48 & 5.7
\end{tabular}

\section{Genetic defects of $\beta$-cell function}

\begin{tabular}{lll} 
MODY & 44 & 5.3 \\
NDM & 7 & 0.8 \\
Mitochondrial & 2 & 0.2 \\
Genetic defects in insulin action & 2 & 0.2 \\
Diseases of exocrine pancreas & & \\
CFRD & 11 & 1.3 \\
Pancreatectomy & 1 & 0.1 \\
Endocrinopathies & 1 & 0.1 \\
Drug-induced & 5 & 0.6 \\
Infections & 1 & 0.1 \\
Genetic syndromes & & \\
Wolfram & 8 & 1 \\
Others & 4 & 0.5 \\
Total & 835 & 100 \\
\hline
\end{tabular}

T1D: type 1 diabetes mellitus, T2D: type 2 diabetes mellitus, MODY: maturity onset diabetes of the young, NDM: neonatal diabetes mellitus, CFRD: cystic fibrosis related diabetes difference was age at diagnosis. Antibody-positive T2D patients were younger than the antibody negative $(11.8 \pm 3.3$ vs $13.7 \pm 1.94, \mathrm{p}=0.045$ ) patients.

A statistically significant increase in the frequency of T2D has clearly been demonstrated in recent years in our cohort with a frequency of $1.9 \%, 2.4 \%$ and $7.9 \%$ in the time periods 1999-2004, 2005-2010 and 2011-2016, respectively $(p<0.001)$ (Figure 1).

The frequency of DKA was $58.4 \%$ and there was also a statistically significant decrease in the proportion of ketoacidosis at diagnosis in T1D after year 2011 (55\% vs $44.6 \%, p=0.022$ ). However, the decrement in the proportion of severe ketoacidosis was not statistically significant (15.1\% vs $9.7 \%, p=0.066)$.

Mean c-peptide levels at diagnosis were $0.7 \pm 0.6 \mathrm{ng} / \mathrm{mL}$ in T1D, $3.2 \pm 1.5 \mathrm{ng} / \mathrm{mL}$ in T2D and $1.3 \pm 0.6 \mathrm{ng} / \mathrm{mL}$ in MODY patients $(p<0.001)$ (Table 2).

In MODY, genetic analysis was available in 26 (59\%) patients and HNF1A and GCK gene mutations were detected in 3 $(11.5 \%)$ and $14(53.8 \%)$ patients, respectively.

Seven patients had NDM and it was molecularly confirmed in 6 of 7 patients in whom KCNJ11 $(\mathrm{n}=2), 6 q 24(\mathrm{n}=1)$, EIF2AK3 $(\mathrm{n}=1)$, SLC19A2 $(\mathrm{n}=1)$ and PTF1A enhancer $(n=1)$ gene mutations were identified.

Table 2 . The clinical features of the patients with type 1 diabetes mellitus, type 2 diabetes mellitus and maturity onset diabetes of the young at diagnosis

\begin{tabular}{|c|c|c|c|c|c|c|c|}
\hline & & & & & $\mathrm{p}$ & & \\
\hline & $\mathrm{n}^{*}$ & T1D & T2D & MODY & $\begin{array}{l}\text { T1D vs } \\
\text { T2D }\end{array}$ & $\begin{array}{l}\text { T1D vs } \\
\text { MODY }\end{array}$ & $\begin{array}{l}\text { T2D vs } \\
\text { MODY }\end{array}$ \\
\hline Gender (F/M) (\%) & 793 & $49 / 51$ & $71 / 29$ & $32 / 68$ & 0.003 & 0.028 & $<0.001$ \\
\hline Age at diagnosis (y) & 793 & $8.4 \pm 4.2$ & $13.2 \pm 2.5$ & $10.2 \pm 3.9$ & $<0.001$ & 0.007 & $<0.001$ \\
\hline Age < 5 years, $n(\%)$ & 793 & $166(23.7 \%)$ & 0 & $5(11.4 \%)$ & $<0.001$ & 0.06 & 0.016 \\
\hline BMI SDS & 560 & $-0.5 \pm 1.3$ & $2.3 \pm 1.0$ & $-0.4 \pm 1.1$ & $<0.001$ & 0.91 & $<0.001$ \\
\hline BMI SDS $\geq 2, n(\%)$ & 560 & $8(1.6 \%)$ & $30(69.8 \%)$ & 0 & $<0.001$ & 0.46 & $<0.001$ \\
\hline C-peptide (ng/mL) & 442 & $0.7 \pm 0.6$ & $3.2 \pm 1.5$ & $1.3 \pm 0.6$ & $<0.001$ & $<0.001$ & $<0.001$ \\
\hline Antibody positivity, n (\%) & 526 & $397(83.1 \%)$ & $4(14.8 \%)$ & 0 & $<0.001$ & $<0.001$ & 0.065 \\
\hline Anti-GAD, n (\%) & 519 & $301(64.2 \%)$ & $2(7.1 \%)$ & 0 & $<0.001$ & $<0.001$ & 0.20 \\
\hline ICA, n (\%) & 511 & $297(64.8 \%)$ & $1(3.7 \%)$ & 0 & $<0.001$ & $<0.001$ & 0.36 \\
\hline IAA, n (\%) & 494 & $147(33 \%)$ & $1(3.7 \%)$ & 0 & $<0.001$ & $<0.001$ & 0.37 \\
\hline $\mathrm{pH}$ & 558 & $7.26 \pm 0.15$ & $7.38 \pm 0.05$ & $7.36 \pm 0.03$ & $<0.001$ & 0.008 & 0.13 \\
\hline $\mathrm{HCO}_{3}(\mathrm{mMol} / \mathrm{L})$ & 547 & $15.1 \pm 7.8$ & $24.6 \pm 5.2$ & $22.7 \pm 3.6$ & $<0.001$ & $<0.001$ & 0.057 \\
\hline DKA, n (\%) & 566 & $251(48.4 \%)$ & $2(6.5 \%)$ & 0 & $<0.001$ & $<0.001$ & 0.29 \\
\hline Severe DKA, n (\%) & 566 & $60(11.6 \%)$ & 0 & 0 & 0.04 & 0.14 & - \\
\hline
\end{tabular}

*: The $n$ values are the number of patients who had available data, T1D: type 1 diabetes mellitus, T2D: type 2 diabetes mellitus, MODY: maturity onset diabetes of the young, F: female, M: male, BMI: body mass index, SDS: standard deviation score, GAD: glutamic acid decarboxylase, ICA: islet cell antibody, IAA: insulin autoantibody, $\mathrm{pH}$ : potential of hydrogen, $\mathrm{HCO}_{3}$ : bicarbonate, DKA: diabetic ketoacidosis 


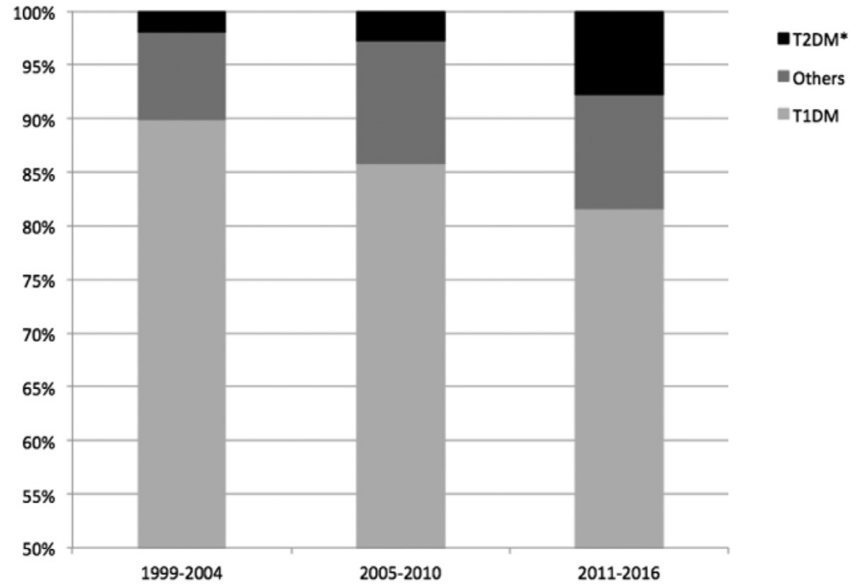

Figure 1. Frequency of type of diabetes in a single-center by 6 year periods

T1DM: type 1 diabetes mellitus, * $\mathrm{p}<0.05$, T2DM: type 2 diabetes mellitus

In eight $(2 \mathrm{~F} / 6 \mathrm{M})$ patients with Wolfram syndrome from five families, three known homozygote/compound heterozygote mutations in WFS gene were detected and four of them had optic atrophy, one had cataract and one had diabetes insipidus.

Cystic fibrosis-related diabetes (CFRD) was detected in 11 patients $(6 \mathrm{~F} / 5 \mathrm{M}, 1.3 \%)$ and the mean age and mean BMI SDS at diagnosis were $12.7 \pm 4.1(5.0-17.4)$ and $-1.4 \pm 1.5$ $(-3.7-1.1)$, respectively.

The frequency of drug-induced diabetes was $0.6 \%(n=5)$, four of which were due to L-asparaginase and one due to tacrolimus.

\section{Discussion}

The present study illuminated some issues concerning the frequency of the different types of diabetes in our population and allowed us to make comparisons with other societies. The overall frequency of T1D, T2D, MODY and other specific types of diabetes were $84 \%, 5.7 \%, 5.3 \%$ and $5 \%$, respectively.

T1D is still the most common cause of childhood diabetes and its frequency varies between $85-95 \%$ in different regions of the world $(3,4,7)$. This variability originates from the number of children with T2D and MODY. The frequencies of T1D, T2D and MODY were $85.6 \%, 10.8 \%$ and $1.2 \%$ respectively in the SEARCH study (USA), while these ratios were $95.5 \%, 1.3 \%$ and $1.5 \%$ respectively in the SWEET study (Europe) $(3,4,9)$. Also, the frequency of MODY was higher (5.5\%) in a recent study from Italy (7). The variation in the frequencies could be explained by the availability of genetic testing and also by prevalence of obesity in that region. Misclassification of diabetes due to the lack of evidence-based clinical criteria for differential diagnosis is widespread and reported to be $7-15 \%$ (10). The diagnosis of MODY (5.3\%) and T2D (5.7\%) was found to be more common in this study as compared to the SWEET study. The present study is not a national multicenter study, so this difference may be explained by referral of the rare types of diabetes to our tertiary center.

The most confusing factor for classification of diabetes is obesity. BMI at the time of diagnosis is a less discriminatory feature for classification (10), since the increase in obesity has led to the appearance of children with obese T1D/ MODY. In different studies, the frequency of obesity among patients with T1D at the time of diagnosis was 3.1-9\% $(11,12)$, but it was $1.6 \%$ in the present study. This could be due to lower obesity rates in our pediatric population (13) compared to North America and Western Europe. Although lower than these regions, obesity rates are also increasing in Turkey which may be the reason for the increase in the frequency of T2D observed over the time span of this study, from $1.9 \%$ to $7.9 \%$. In accordance with previous reports (14), T2D was more common in girls and at pubertal ages.

The antibody positivity in T2D is reported up to $15 \%$ and these antibody-positive patients are usually younger, less overweight/obese and have higher hemoglobin A1c values (15). So, several terminologies have been recommended such as double diabetes, type 1.5 diabetes and latent autoimmune diabetes of youth. In the present study, the antibody positivity was $14.8 \%$ and there was a significant difference between antibody positive and negative subjects only at the age of diagnosis, with a younger age of diagnosis being seen in antibody positive patients, in line with other reports. Although, a few case reports described antibody positive MODY patients, the prevalence of antibody positivity in MODY is < $1 \%$ (16). Therefore, the antibody positivity was used as an exclusion criterion for MODY in the present study.

The frequency of DKA in T1D varied from $48 \%$ to $66 \%$ in the different studies in Turkey $(17,18,19)$. Our study shows a decrease of $10 \%$ in the rate of DKA at the time of diagnosis, albeit, the current ratio is still high. DKA at the time of diagnosis of pediatric T2D is not infrequent and is reported to be as high as $40 \%$ of patients (15). However, it was not frequent in our study (4.2\%) but nearly one-third of patients with T2D presented with ketosis without acidosis.

The frequency of MODY varies between $0.83-5.5 \%$ in different studies $(4,6,7,20,21,22,23)$. GCK mutation (up to $95 \%$ ) was the most common cause in the studies that reported higher MODY frequency $(6,7,22)$. Similarly, we 
detected GCK mutation in $53.8 \%$ of the clinically MODY patients who were genetically tested. This can be explained by the widespread use of random glucose measurement in general pediatric clinics in Turkey. On the other hand, the rate of genetic analysis in the clinical MODY patients was low (59\%) in the present study, as it was not possible to perform this analysis prior to 2010 . In $65.3 \%$ of these patients a mutation in one of the known MODY genes could be detected. This ratio varies between $27-89 \%$ in different studies (24). This variation and failure to detect mutations may result from inclusion criteria for genetic testing, may be due to a mutation in a gene not yet identified or to diagnostic overlap of different types of diabetes.

$\mathrm{C}$ peptide levels, although useful in long-standing diabetes cases, might not be discriminative in patients with new onset diabetes because of substantial overlap among different types of diabetes mellitus (25). Nevertheless, in addition to autoantibody positivity, c-peptide levels remain a relatively good diagnostic parameter. In the present study, c-peptide levels at the time of diagnosis were helpful, especially in differentiating between T1D and T2D.

\section{Study Limitations}

The limitation of this study is that it included a tertiary center data. Therefore, the frequency of some specific types of diabetes as CFRD may not reflect real frequency.

\section{Conclusion}

The present study provides trends over the last 17 years in pediatric diabetes in a large number of patients, from a single tertiary center and tries to identify the distinguishing features of each of different types of diabetes. The frequency of T2D is increasing but is still lower than that in North America. MODY is becoming more easily recognized in recent years owing to availability of autoantibody testing and genetic tests. Despite overlapping features such as obesity, ketosis and antibody positivity, there are demographic (age, puberty, gender, family history) as well as laboratory (autoantibody positivity, c-peptide) tools to correctly identify the type of diabetes in the pediatric population.

\section{Acknowledgement}

We would like to thank to all medical doctors, students and staff who were working in our institution between 19992016 for their efforts.

\section{Ethics}

Ethics Committee Approval: This study approved by Ethical Committee of Marmara University (approval no: 09.2013.0408).
Informed Consent: Retrospective study.

Peer-review: Externally peer-reviewed.

\section{Authorship Contributions}

Surgical and Medical Practices: Zeynep Atay, Tülay Güran, Serap Turan, Serpil Baş, Concept: Abdullah Bereket, Design: Belma Haliloğlu, Data Collection or Processing: Sayğın Abalı, Fuat Buğrul, Enes Çelik, Analysis or Interpretation: Saygin Abalı, Literature Search: Belma Haliloğlu, Writing: Belma Haliloğlu, Abdullah Bereket.

Financial Disclosure: The authors declared that this study received no financial support.

\section{References}

1. Patterson CC, Dahlquist GG, Gyürüs E, Green A, Soltész G; EURODIAB Study Group. Incidence trends for childhood type 1 diabetes in Europe during 1989-2003 and predicted new cases 2005-20: a multicentre prospective registration study. Lancet 2009;373::2027-2033. Epub 2009 May 27

2. Patterson C, Guariguata L, Dahlquist G, Soltész G, Ogle G, Silink M. Diabetes in the young - a global view and worldwide estimates of numbers of children with type 1 diabetes. Diabetes Res Clin Pract 2014;103:161-175. Epub 2013 Dec 1

3. Pettitt DJ, Talton J, Dabelea D, Divers J, Imperatore G, Lawrence JM, Liese AD, Linder B, Mayer-Davis EJ, Pihoker C, Saydah SH, Standiford DA, Hamman RF; SEARCH for Diabetes in Youth Study Group. Prevalence of diabetes in U.S. youth in 2009: the SEARCH for diabetes in youth study. Diabetes Care 2014;37:402-408. Epub 2013 Sep 16

4. Pacaud D, Schwandt A, de Beaufort C, Casteels K, Beltrand J, Birkebaek $\mathrm{NH}$, Campagnoli M, Bratina N, Limbert C, Mp O'Riordan S, Ribeiro R, Gerasimidi-Vazeou A, Petruzelkova L, Verkauskiene R, Krisane ID; SWEET Study Group. A description of clinician reported diagnosis of type 2 diabetes and other non-type 1 diabetes included in a large international multicentered pediatric diabetes registry (SWEET). Pediatr Diabetes 2016;17(Suppl 23):24-31.

5. Ehtisham S, Hattersley AT, Dunger DB, Barrett TG; British Society for Paediatric Endocrinology and Diabetes Clinical Trials Group. First UK survey of paediatric type 2 diabetes and MODY. Arch Dis Child 2004;89:526-529

6. Mozzillo E, Salzano G, Barbetti F, Maffeis C, Lombardo F, Franzese A, Delvecchio M, Marigliano M. Survey on etiological diagnosis of diabetes in 1244 Italian diabetic children and adolescents: impact of access to genetic testing. Diabetes Res Clin Pract 2015;107:15-18. Epub 2015 Jan 20

7. Delvecchio M, Mozzillo E, Salzano G, Iafusco D, Frontino G, Patera PI, Rabbone I, Cherubini V, Grasso V, Tinto N, Giglio S, Contreas G, Di Paola R, Salina A, Cauvin V, Tumini S, d'Annunzio G, Iughetti L, Mantovani V, Maltoni G, Toni S, Marigliano M, Barbetti F; Diabetes Study Group of the Italian Society of Pediatric Endocrinology and Diabetes (ISPED). Monogenic Diabetes accounts for $6.3 \%$ of cases referred to 15 Italian pediatric diabetes Centers during 2007-2012. J Clin Endocrinol Metab 2017;102:1826-1834

8. Rubio-Cabezas O, Hattersley AT, Njølstad PR, Mlynarski W, Ellard S, White N, Chi DV, Craig ME; International Society for Pediatric and Adolescent Diabetes. ISPAD Clinical Practice Consensus Guidelines 2014. The diagnosis and management of monogenic diabetes in children and adolescents. Pediatr Diabetes 2014;15(Suppl 20):47-64. 
9. Pihoker C, Gilliam LK, Ellard S, Dabelea D, Davis C, Dolan LM, Greenbaum CJ, Imperatore G, Lawrence JM, Marcovina SM, MayerDavis E, Rodriguez BL, Steck AK, Williams DE, Hattersley AT; SEARCH for Diabetes in Youth Study Group. Prevalence, characteristics and clinical diagnosis of maturity onset diabetes of the young due to mutations in HNF1A, HNF4A, and glucokinase: results from the SEARCH for Diabetes in Youth. J Clin Endocrinol Metab 2013;98:40554062. Epub 2013 Jun 14

10. Shields BM, Peters JL, Cooper C, Lowe J, Knight BA, Powell RJ, Jones A, Hyde CJ, Hattersley AT. Can clinical features be used to differentiate type 1 from type 2 diabetes? A systematic review of the literature. BMJ Open 2015;5:e009088.

11. Manyanga T, Sellers EA, Wicklow BA, Doupe M, Fransoo R. Is the change in body mass index among children newly diagnosed with type 1 diabetes mellitus associated with obesityat transition from pediatric to adult care? Pediatr Diabetes 2016;17:599-607. Epub 2016 Jan 8

12. Redondo MJ, Connor CG, Ruedy KJ, Beck RW, Kollman C, Wood JR, Buckingham B, Klingensmith GJ, Silverstein J, Tamborlane WV; Pediatric Diabetes Consortium. Pediatric Diabetes Consortium Type 1 Diabetes New Onset (NeOn) Study: factors associated with HbA1c levels one year after diagnosis. Pediatr Diabetes 2014;15:294-302. Epub 2013 Jul 24

13. Bereket A, Atay Z. Current status of childhood obesity and its associated morbidities in Turkey. J Clin Res Pediatr Endocrinol 2012;4:1-7.

14. Nadeau KJ, Anderson BJ, Berg EG, Chiang JL, Chou H, Copeland KC, Hannon TS, Huang TT, Lynch JL, Powell J, Sellers E, Tamborlane WV, Zeitler P. Youth-Onset Type 2 Diabetes Consensus Report: Current Status, Challenges, and Priorities. Diabetes Care 2016;39:1635-1642. Epub 2016 Aug 2

15. Zeitler P. Approach to the obese adolescent with new-onset diabetes. J Clin Endocrinol Metab 2010;95:5163-5170.

16. McDonald TJ, Colclough K, Brown R, Shields B, Shepherd M, Bingley P, Williams A, Hattersley AT, Ellard S. Islet autoantibodies can discriminate maturity-onset diabetes of the young (MODY) from Type 1 diabetes. Diabet Med 2011;28:1028-1033.

17. Hatun S.. Diabetes program at schools in Turkey. J Clin Res Pediatr Endocrinol 2012;4:114-115.
18. Demir F, Günöz H, Saka N, Darendeliler F, Bundak R, Baş F, Neyzi O. Epidemiologic Features of Type 1 Diabetic Patients between 0 and 18 Years of Age in İstanbul City. J Clin Res Pediatr Endocrinol 2015;7:4956.

19. Ardicli D, Kandemir N, Alikasifoglu A, Ozon A, Gonc N. Clinical characteristics of type 1 diabetes over a 40 year period in Turkey: secular trend towards earlier age of onset. J Pediatr Endocrinol Metab 2014;27:635-641.

20. Demirbilek H, Özbek MN, Baran RT. Incidence of type 1 diabetes mellitus in Turkish children from the southeastern region of the country: a regional report. J Clin Res Pediatr Endocrinol 2013;5:98-103.

21. Schober E, Rami B, Grabert M, Thon A, Kapellen T, Reinehr T, Holl RW; DPV-Wiss Initiative of the German Working Group for Paediatric Diabetology and. Phenotypical aspects of maturity-onset diabetes of the young (MODY diabetes) in comparison with Type 2 diabetes mellitus(T2DM) in children and adolescents: experience from a large multicentre database. Diabet Med 2009;26:466-473.

22. Fendler W, Borowiec M, Baranowska-Jazwiecka A, Szadkowska A, SkalaZamorowska E, Deja G, Jarosz-Chobot P, Techmanska I, BautembachMinkowska J, Mysliwiec M, Zmyslowska A, Pietrzak I, Malecki MT, Mlynarski W. Prevalence of monogenic diabetes amongst Polish children after a nationwide genetic screening campaign. Diabetologia 2012;55:2631-2635. Epub 2012 Jul 11

23. Małachowska B, Borowiec M, Antosik K, Michalak A, BaranowskaJazwiecka A, Deja G, Jarosz-Chobot P, Brandt A, Mysliwiec M, Stelmach M, Nazim J, Peczynska J, Głowinska-Olszewska B, Horodnicka-Józwa A, Walczak M, Małecki MT, Zmysłowska A, Szadkowska A, Fendler W, Młynarski W. Monogenic diabetes prevalence among Polish childrenSummary of 11 years-long nationwide genetic screening program. Pediatr Diabetes 2018;19:53-58. Epub 2017 Apr 24

24. Irgens HU, Molnes J, Johansson BB, Ringdal M, Skrivarhaug T, Undlien DE, Søvik O, Joner G, Molven A, Njølstad PR. Prevalence of monogenic diabetes in the population-based Norwegian Childhood Diabetes Registry. Diabetologia 2013;56:1512-1519. Epub 2013 Apr 27

25. Kleinberger JW, Pollin TI. Undiagnosed MODY: Time for Action. Curr Diab Rep 2015;15:110.

26. Jones AG, Hattersley AT. The clinical utility of C-peptide measurement in the care of patients with diabetes. Diabet Med 2013;30:803-817. 